\title{
Hysteroscopic evaluation of postmenopausal bleeding patients and its correlation with histopathological examination
}

\author{
Sudhir Mansingh ${ }^{1}$, Atmajit Singh Dhillon², Sandeep Sood ${ }^{1}$, Sirisha Anne ${ }^{1 *}$, Prema Godi ${ }^{1}$
}

\begin{abstract}
${ }^{1}$ Department of Obstetrics and Gynecology, Command Hospital Lucknow, Uttar Pradesh, India
${ }^{2}$ Department of Obstetrics and Gynecology, Maharishi Markendeshwar Institute of Medical Sciences and Research, Maulana, Haryana, India
\end{abstract}

Received: 09 June 2020

Accepted: 08 July 2020

\author{
*Correspondence: \\ Dr. Sirisha Anne, \\ E-mail: siri1407@gmail.com
}

Copyright: (C) the author(s), publisher and licensee Medip Academy. This is an open-access article distributed under the terms of the Creative Commons Attribution Non-Commercial License, which permits unrestricted non-commercial use, distribution, and reproduction in any medium, provided the original work is properly cited.

\begin{abstract}
Background: Menopause is defined according to WHO as the permanent cessation of menstruation resulting from the loss of ovarian follicular activity. It is defined as uterine bleeding occurring after at least 1 year of amenorrhoea. Considering the high accuracy of hysteroscopy in evaluation of postmenopausal bleeding, the present study was carried out with an aim to evaluate hysteroscopic findings in women with postmenopausal bleeding in order to assess the causes of PMB and to determine their prevalence in our population.

Methods: This was a prospective observation study, comprising of total number of 50 postmenopausal women attending gynae OPD at department of obstetrics and gynecology, Command Hospital $(\mathrm{CH})$, Lucknow, Uttar Pradesh. The data obtained for the purpose of study was fed into computer using Microsoft excel 2013 software.

Results: A total of 50 women with complaints of postmenopausal bleeding were enrolled in the study. Maximum number of women had achieved menopause between age 46 and 50 years. Hysteroscopy had an accuracy of $94 \%$ for detection of polyps. Hysteroscopy had an accuracy of $90 \%$ for detection of atrophy. For fibroid, hysteroscopy had an absolute sensitivity, specificity, positive predictive, negative predictive and accuracy value (100\%).

Conclusions: The findings of present study suggested that hysteroscopy has a useful role in evaluation of postmenopausal bleeding especially in the diagnosis of polyps and fibroids. Given fewer number of cases, the usefulness of hysteroscopy in evaluation of endometrial cancer and hyperplasia could not be established adequately. Further studies on larger number of sample size will help in providing more useful and confirmatory information.
\end{abstract}

Keywords: Endometrial polyps, Hysteroscopy, Post-menopausal bleeding

\section{INTRODUCTION}

Menopause is defined according to WHO as the permanent cessation of menstruation resulting from the loss of ovarian follicular activity. ${ }^{1}$ Bleeding after menopause is an abnormality and is termed as postmenopausal bleeding (PMB). It is defined as uterine bleeding occurring after at least 1 year of amenorrhoea. Postmenstrual bleeding is a common complaint among patients visiting a gynecologists and comprises nearly 5$10 \%$ of total patient turnover to a gynaecology clinic. ${ }^{2}$
It is important to ascertain the exact cause of postmenopausal bleeding in order to understand the urgency of the situation and to offer appropriate treatment. In the recent years, transvaginal sonography has also become a useful tool in the assessment of postmenopausal bleeding. Although, in almost half the cases, clinical assessment, transvaginal sonography and/or saline infusion sonography are able to diagnose and detect the cause of postmenopausal bleeding yet in a large proportion of cases, the diagnosis remains uncertain and needs to be validated. 
In the past, in cases where a definitive diagnosis cannot be arrived through clinical or imaging modalities, dilatation and curettage for collection of endometrial tissue for histopathological examination was the only recourse available. However, there is always a difficulty in missing the precise site of intrauterine lesion and thus missing the opportunity of a correct histopathological diagnosis. With the introduction of hysteroscopy, the chances of getting a correct diagnosis have enhanced tremendously. Hysteroscopy enables to directly visualize the uterine cavity completely and in case of any abnormal visualization, the representative tissue can be collected for histopathological examination.

Hysteroscopy is an easy to perform office procedure that can be done in a short period of time without causing discomfort to patients and their attendants. It is a widely recognized diagnostic modality in the evaluation of abnormal uterine bleeding in premenopausal, perimenopausal and post-menopausal cases with high accuracy. It is highly accurate for diagnosing endouterine lesions such as polyps, submucous myomas, endometrial adenocarcinoma and hyperplasia, i.e., the conditions associated with postmenopausal bleeding.

Considering the high accuracy of hysteroscopy in evaluation of postmenopausal bleeding, the present study was carried out with an aim to evaluate hysteroscopic findings in women with postmenopausal bleeding in order to assess the various causes of PMB and to determine their prevalence in our population.

\section{METHODS}

This was a prospective observation study, comprising of total number of 50 postmenopausal women attending gynae OPD at department of obstetrics and gynecology, Command Hospital $(\mathrm{CH})$, Lucknow, Uttar Pradesh. The study was carried out over 1 year from July 2018 to June 2019. Postmenopausal women with UV Prolapse, bleeding diathesis, surgical menopause and cardiac diseases were excluded from the study.

After taking detailed history and thorough clinical examination, patients are subjected to transvaginal sonography followed by hysteroscopy with office hysteroscope. After decision and patient selection for office hysteroscopy, pre-procedure counseling was done. Patient was sufficiently explained what hysteroscopy is, the objectives of performing the procedure, and expected results. Tablet misoprostol 400 microgram was inserted per-vaginum 3-4 hours prior to the procedure by the woman. Authors also avoided the use of any local anesthesia/analgesia/premedication. The patient was observed in a side room after the procedure for some time and was sent home with a prescription of analgesic if required. Hysteroscope (Karl Storz) $4 \mathrm{~mm}$ scope with $5 \mathrm{~mm}$ sheath with an oblique lens of 30 degrees with ringer lactate as distention media and camera (Karl Storz telecom II camera) was used which was connected to the monitor via VCR, which helped us record interesting cases. A standard hysteroscopy tray containing vaginal speculum, valsellum, uterine sound and graduated cervical dilators was kept ready and these instruments were used only in cases of difficult negotiation of cervical os and in cases where endometrial biopsy was taken.

Under strict asepsis, the procedure was initiated with vaginoscopy approach, without introducing any other instruments, other than the scope, which reduced significantly the pain felt as well as chance of trauma and bleeding during the procedure, increasing its acceptability to the patient. The findings of hysteroscopy were noted and endometrial biopsy was sent for histopathological examination. The other instruments like speculum, valsellum, uterine manipulator, artery forceps with biopsy syringe were used in case of abnormal findings where endometrial biopsy (EB) was required, or in case of requirement for removal of small intrauterine polyp/ $\mathrm{CuT}$.

The confidentiality of the study subject was maintained as per Good Clinical Practice Guidelines by Govt. of India. The data obtained for the purpose of study was fed into computer using Microsoft excel 2013 software. Data analysis was performed using statistical package for social sciences, version 21.0. Diagnostic efficacy of hysteroscopy was expressed in terms of sensitivity, specificity, positive predictive value, negative predictive value and accuracy respectively.

\section{RESULTS}

The present study was carried out to evaluate hysteroscopically the causes of post-menopausal bleeding. For this purpose, a total of 50 women with complaints of postmenopausal bleeding were enrolled in the study.

Table 1: General profile of the women enrolled in the study.

\begin{tabular}{|ll|}
\hline Characteristic & Statistic \\
\hline Age & \\
\hline $41-50$ years & $10(20 \%)$ \\
\hline $51-60$ years & $23(46 \%)$ \\
\hline $61-70$ years & $11(22 \%)$ \\
\hline$>70$ years & $6(12 \%)$ \\
\hline Mean age \pm SD (range) in years & $58.42 \pm 8.93(41-$ \\
$80)$ \\
\hline Place of residence \\
\hline Rural \\
\hline Urban & $24(48 \%)$ \\
\hline Occupation & $26(52 \%)$ \\
\hline Home-maker & $48(96 \%)$ \\
\hline Working & $2(4 \%)$ \\
\hline Socioeconomic status & \\
\hline Middle & $38(76 \%)$ \\
\hline Upper middle & $12(24 \%)$ \\
\hline
\end{tabular}


Table 1 shows the general profile of the women enrolled in the study. Age of patients ranged from 41 to 80 years. Maximum $(\mathrm{n}=23 ; 46 \%)$ were aged 51-60 years followed by those aged $61-70$ years $(22 \%), 41-50$ years $(20 \%)$ and $>70$ years $(12 \%)$ respectively. Mean age of patients was $58.42 \pm 8.93$ years. Majority of patients were from urban $(52 \%)$ regions. A total of $24(48 \%)$ were from rural areas. Except for $2(4 \%)$ working women, all the others were homemakers. Socioeconomically, those from middle socioeconomic group were dominant $(n=38 ; 76 \%)$ followed by upper-middle socioeconomic group $(n=12$; $24 \%)$.

\section{Table 2: Distribution of cases according to other presenting complaints.}

\begin{tabular}{|lll|}
\hline Complaint & No. of cases & Percentage \\
\hline $\begin{array}{l}\text { Pain abdomen/ } \\
\text { suprapubic pain }\end{array}$ & 7 & $14 \%$ \\
\hline Vaginal dryness & 17 & $34 \%$ \\
\hline Decreased libido & 32 & $64 \%$ \\
\hline Insomnia & 9 & $18 \%$ \\
\hline Post-coital bleeding & 2 & $4 \%$ \\
\hline Dyspareunia & 1 & $2 \%$ \\
\hline
\end{tabular}

Table 3: Hysteroscopic findings.

\begin{tabular}{|lll|}
\hline Finding & No. of cases & Percentage \\
\hline Unhealthy cervix & 7 & $14.0 \%$ \\
\hline Atrophy & 8 & $16.0 \%$ \\
\hline Polyp & 25 & $50.0 \%$ \\
\hline Fibroid & 5 & $10.0 \%$ \\
\hline Hyperplasia & 1 & $2.0 \%$ \\
\hline Endometrial carcinoma & 3 & $6.0 \%$ \\
\hline Degenerative changes & 1 & $2.0 \%$ \\
\hline
\end{tabular}

Table 2 shows distribution of cases according to other presenting complaints. Decreased libido (64\%), vaginal dryness (34\%), insomnia (18\%) and pain abdomen/suprapubic pain $(14 \%)$ were the most common presenting complaints. There were two cases (4\%) complaining of post-coital bleeding and 1 (2\%) complaining of dyspareunia.
Maximum number of women had achieved menopause between age 46 and 50 years $(n=14 ; 28 \%)$ followed by those aged $41-45$ and $51-55$ years $(n=11 ; 22 \%$ each $),<40$ years $(\mathrm{n}=9 ; 18 \%)$ and $56-60$ years $(\mathrm{n}=5 ; 10 \%)$ respectively. Mean age at achievement of menopause was $47.50 \pm 5.88$ years.

Table 4: Final diagnosis (based on biopsy/ HPE).

\begin{tabular}{|lll|}
\hline Diagnosis & No. of cases & Percentage \\
\hline Normal & 1 & $2.0 \%$ \\
\hline Atrophy & 13 & $26.0 \%$ \\
\hline Polyp & 22 & $44.0 \%$ \\
\hline Fibroid & 5 & $10.0 \%$ \\
\hline Hyperplasia & 4 & $8.0 \%$ \\
\hline Endometrial carcinoma & 5 & $10.0 \%$ \\
\hline
\end{tabular}

Time since achievement of menopause ranged from 1.1 to 40 years. Maximum $(n=24 ; 48 \%)$ had achieved menopause for $>10$ years, $9(18 \%)$ each had achieved menopause <2 years and 3-5 years back while 8 (16\%) had achieved menopause 6-10 years back. Mean time since achievement of menopause was $11.18 \pm 8.66$ years.

Pap smear cytological findings were in general indicative of inflammatory/non-neoplastic lesions in 44 (88\%) cases. In 5 (10\%) cases, they were unsatisfactory/inadequate while in $1(2 \%)$ case it was diagnosed as CIN III.

Table 3 shows Hysteroscopic findings. On hysteroscopy, half the cases $(n=25 ; 50 \%)$ were diagnosed as polyps followed by atrophic endometrium $(n=8 ; 16 \%)$. There were $7(14 \%)$ cases in whom the cervix was classified as unhealthy without any particular diagnosis. A total of 5 (10\%) cases were diagnosed as fibroid, 1 (2\%) each as hyperplasia and degenerative changes and $3(6 \%)$ as endometrial carcinoma.

Table 4 shows final diagnosis, in $1(2 \%)$ case, no abnormality was seen. There were $13(26 \%)$ cases diagnosed as atrophy, $22(44 \%)$ as polyps, $5(10 \%)$ each fibroid and endometrial carcinoma and $4(8 \%)$ as hyperplasia.

Table 5: Diagnostic efficacy of hysteroscopy for different endometrial abnormalities.

\begin{tabular}{|llllll|}
\hline & Sensitivity & Specificity & PPV & NPV & Accuracy \\
\hline Polyp & 100 & 89.3 & 89.3 & 100 & 94.0 \\
\hline Atrophy & 61.5 & 100 & 100 & 88.1 & 90.0 \\
\hline Fibroid & 100 & 100 & 100 & 100 & 100 \\
\hline Endometrial cancer & 60 & 100 & 100 & 95.7 & 96.0 \\
\hline Hyperplasia & 25 & 100 & 100 & 93.9 & 94.0 \\
\hline
\end{tabular}

Table 5 shows diagnostic efficacy of hysteroscopy for different endometrial abnormalities. All the 22 cases diagnosed as polyp on biopsy/HPE were detected as polyps by hysteroscopy. Hysteroscopy additionally 
detected three cases as polyps (1 atrophy and 2 hyperplasia on final diagnosis). Thus, for polyps, there were 22 true positive, 3 false positive, no false negative and 25 true negative cases. Hence, corresponding sensitivity, specificity, positive predictive value and negative predictive values were $100 \%, 89.3 \%, 89.3 \%$ and $100 \%$ respectively. Hysteroscopy had an accuracy of $94 \%$ for detection of polyps.

Histopathologically, there were 13 cases of atrophy, however, hysteroscopy could detect only 8 of them successfully. Remaining 5 cases were diagnosed as unhealthy cervix $(n=4)$ and polyp $(n=1)$ by hysteroscopy. Thus, for atrophy, there were 8 true positive, no false positive, 5 false negative and 37 true negative cases. Hence, corresponding sensitivity, specificity, positive predictive value and negative predictive values were $61.5 \%, 100 \%, 100 \%$ and $88.1 \%$ respectively. Hysteroscopy had an accuracy of $90 \%$ for detection of atrophy.

All the 5 cases confirmed as fibroid on final diagnosis were also diagnosed as fibroid by hysteroscopy. There was no false positive or false negative case. Hence, for fibroid, hysteroscopy had an absolute sensitivity, specificity, positive predictive, negative predictive and accuracy value $(100 \%)$.

Out of 5 cases confirmed as endometrial cancer by final diagnosis, 3 were diagnosed as endometrial cancer by hysteroscopy, however, 1 each was diagnosed as degenerative changes and unhealthy cervix respectively by hysteroscopy. Thus, for endometrial cancer, there were 3 true positive, no false positive, 2 false negative and 45 true negative cases and corresponding sensitivity, specificity, PPV, NPV and accuracy values of hysteroscopy were 60\%, 100\%, 100\%, 95.7\% and 96\% respectively.

Out of 4 cases confirmed as hyperplasia, hysteroscopy could diagnose only 1 case as hyperplasia successfully, while 2 were diagnosed wrongly as polyp and 1 as unhealthy cervix respectively. Thus, for hyperplasia, there was 1 true positive, no false positive, 3 false negative and 46 true negative cases and corresponding sensitivity, specificity, PPV, NPV and accuracy values of hysteroscopy were $25 \%, 100 \%, 100 \%, 93.9 \%$ and $94 \%$ respectively.

\section{DISCUSSION}

Considering the usefulness of hysteroscopy in evaluation of postmenopausal bleeding, in present study authors carried out hysteroscopic evaluation of postmenopausal women as per the recommended guidelines.

In present study, age of women ranged from 41 to 80 years with a mean age of 58.42 years. Majority of patients $(66 \%)$ were in age range 41 to 60 years. The mean age of women with postmenopausal bleeding undergoing hysteroscopic evaluation has shown a considerable variability in different studies. Ribeiro et al, in a study from Brazil reported it as 61.1 years. ${ }^{3}$ In a study from Portugal, Metello et al, reported it as 61.5 years but another study from Portugal reported it to be 64.9 years while Tinelli et al, from Italy reported it to be 58.6 years which is similar to this study. ${ }^{4-6}$ Back home, in an Indian study, similar to this study the major concentration of women was seen in the age range 50-55 years. $^{7}$ Nagalakshmi et al, in another study from India reported the mean age of women as 54.76 years. ${ }^{8}$ Junnare et al, too reported the mean age of women in their study as 53.15 years. ${ }^{9}$ Relatively younger age profile of women in studies from Asian countries as compared to those from western countries could be attributable to a relatively lower age of menopause. As per an estimate, the average age of menopause in Asian women is 46 years. $^{7}$

In present study, majority of patients were from urban areas $(52 \%)$, were non-working homemakers $(96 \%)$ and belonged to middle socioeconomic strata (76\%). Compared to present study, a number of studies have reported a dominance of rural women from lower socioeconomic class. ${ }^{10,11}$ There could be two reasons for this difference, first, this study centre is located in an urban area, despite that almost half $(48 \%)$ of women were from rural areas, secondly as far as socioeconomic class is concerned, study facility primarily caters to Armed Forces personnel and their dependents who belong to middle or upper-middle classes of society. Nevertheless, it might not be ruled out that the lower representation of patients from upper classes indicates the need of proper awareness regarding preventive measures and hygiene related issues. Another reason for this could be cited as lack of accessibility to specialized services to women from lower socioeconomic strata.

In present study, except for postmenopausal bleeding, decreased libido (64\%), vaginal dryness (34\%) and insomnia (18\%) were the most common presenting complaints. All these complaints could be associated with hormonal changes associated with menopause. With the onset of menopause, the estrogen secretion is decreased which is responsible for decreased sexual drive and is also responsible for symptoms like vaginal dryness. ${ }^{12,13}$ These hormonal changes are also responsible for postmenopausal bleeding in some cases.

In present study, majority of women had attained menopause before the age of 50 years $(68 \%)$. Mean age at menopause was $47.50 \pm 5.88$ years. This finding is in agreement with the average age of menopause in Asian women which is reported as 46 years. $^{7}$

In present study, maximum number of women (48\%) had attained menopause $>10$ years back. Mean duration since menopause was $11.18 \pm 8.66$ years. Nagalakshmi et al, reported this gap to be 7.95 years among symptomatic women. ${ }^{8}$ 
In present study, mean years of married life were $40.76 \pm 9.35$ years. Median parity was P3. Almost half (52\%) were sexually active. Compared to present study Tandulwadker et al, in their study reported median parity as primipara. $^{7}$ In their study, there were only $8(13.3 \%)$ multipara. Compared to their study, in present study the proportion of multipara women was much higher.

In present study, history of drug use (52\%), gynecological procedures (36\%), hypertension (32\%), diabetes $(24 \%)$, hypothyroidism $(4 \%)$ and general surgical procedures $(22 \%)$ were the most common medical and surgical histories present. Hypertension and diabetes are major metabolic issues and could in turn affect other systemic and hormonal equilibrium. Similarly, drug use could also influence the normal physiological mechanism. However, one must not forget that the average age of women was nearly 60 years, where metabolic disorders like hypertension and diabetes are quite common, especially in an urban environment. Obesity, hypertension, diabetes and other lifestyle and reproductive factors have been recognized as the factors associated with post-menopausal bleeding that also enhance the risk of endometrial cancer. ${ }^{14,15}$

In present study, $11(22 \%)$ women were in overweight and obese category too. Comorbid conditions like diabetes, hypertension, hypothyroidism and obesity have often been encountered in women with postmenopausal bleeding. In a study by Tandulwadkar et al, diabetes, hypertension, hypothyroidism and obesity were seen in $20 \%, 13.33 \%, 5 \%$ and $13.33 \%$ patients respectively. They also found that majority of their cases with endometrial cancer had these factors. ${ }^{7}$

Table 6: Hysteroscopic findings in postmenopausal bleeding cases in some of the contemporary studies.

\begin{tabular}{|c|c|c|}
\hline $\begin{array}{l}\text { Author (year), } \\
\text { location }\end{array}$ & No. of cases and characteristics & Hysteroscopic findings \\
\hline Ribero et $\mathrm{al}^{3}$, Brazil & 510 mean age $61.1 \pm 2.0$ years & $\begin{array}{l}\text { Polyps }(67.5 \%) \text {, cancer/hyperplasia }(8.7 \%) \text {, myomas } \\
(7.3 \%) \text {, normal }(4.5 \%) \text {, others }(11.9 \%)\end{array}$ \\
\hline $\begin{array}{l}\text { Tandulwadkar et } \mathrm{al}^{7} \text {, } \\
\text { India }\end{array}$ & $60(81.6 \%>50$ years $)$ & $\begin{array}{l}\text { Atrophy }(65 \%), \text { hyperplasia }(6.67 \%) \text {, polyp }(11.7 \%) \text {, } \\
\text { submucous fibroid }(1.7 \%) \text {, endometrial carcinoma } \\
(11.7 \%)\end{array}$ \\
\hline $\begin{array}{l}\text { Pop-Trajkoviü- } \\
\text { Diniü }{ }^{23}, \text { Serbia }\end{array}$ & 148 (mean age 69 years) & $\begin{array}{l}\text { Normal }(26.2 \%) \text {, endometrial polyp }(29.6 \%) \text {, cervical } \\
\text { polyp }(16.5 \%) \text {, submucous myoma }(5.51 \%) \text {, endometrial } \\
\text { hyperplasia }(7.58 \%) \text {, atrophy }(12.5 \%) \text {, endometrial cancer } \\
(2.06 \%)\end{array}$ \\
\hline Gupta et $\mathrm{al}^{20}$, India & 70 (50 peri, 20 postmenopausal) & $\begin{array}{l}\text { Normal (42.85\%), endometrial polyp (11\%), fibroid } \\
(27.14 \%), \text { endometrial hyperplasia }(20 \%)\end{array}$ \\
\hline Sarvi et $\mathrm{al}^{21}$, Turkey & $\begin{array}{l}110 \text { (mean age } 57 \text { years, } 67- \\
\text { AUB, } 43 \text { thickened endometrium) }\end{array}$ & $\begin{array}{l}\text { Normal }(15.5 \%), \text { polyp }(48.2 \%), \text { myoma }(18.2 \%) \text {, } \\
\text { hyperplasia }(14.5 \%) \text {, carcinoma }(3.6 \%)\end{array}$ \\
\hline $\begin{array}{l}\text { Sharma and Tiwari }{ }^{22} \text {, } \\
\text { Nepal }\end{array}$ & $\begin{array}{l}50 \text { Peri and post-menopausal aged } \\
45 \text { to } 64 \text { years }\end{array}$ & $\begin{array}{l}\text { Normal }(34 \%) \text {, hyperplastic (36\%), atrophy }(18 \%) \text {, } \\
\text { endometrial polyp }(6 \%) \text {, cervical polyp }(2 \%) \text {, endometrial } \\
\text { carcinoma ( } 4 \%)\end{array}$ \\
\hline Junnare et $\mathrm{al}^{9}$, India & $98(87 \%$ aged $\leq 60$ years $)$ & $\begin{array}{l}\text { Normal (36\%), atrophy (19\%), hyperplastic (30\%), } \\
\text { endometrial polyp (13\%), posterior wall growth }(1 \%)\end{array}$ \\
\hline Present study, India & 50 (mean age 58.42 years) & $\begin{array}{l}\text { Unhealthy cervix/normal (14\%), atrophy (16\%), polyp } \\
(50 \%) \text {, fibroid/ myoma }(10 \%) \text {, hyperplasia }(2 \%) \text {, } \\
\text { endometrial cancer }(6 \%) \text {, degenerative changes not } \\
\text { otherwise classified }(2 \%)\end{array}$ \\
\hline
\end{tabular}

In present study, no particular dietary, bowel or bladder disorder or personal habit was recorded as a risk factor. Majority were vegetarian $(54 \%)$ and did not have appetite problems $(96 \%)$. There was no woman with sleep, bowel or bladder abnormality. None of the women were smoker or alcohol user. No other habit was reported.

In present study, general and systemic examination findings were generally normal and did not give a particular notion towards any hormonal or physiological abnormality. Though, one patient had abnormally raised serum creatinine level indicative of renal dysfunction, however, it is rarely reported as the cause of vaginal bleeding. ${ }^{16}$ Though coagulation abnormalities and chronic renal failure may cause menorrhagia, however, none of the patients in present study were known cases of chronic renal disease. ${ }^{17}$

As such after ruling out different physiological and hormonal reasons, and a suspicious TVS finding, the focus was mainly towards finding out a pathological cause of postmenopausal bleeding. For the screening 
purpose, cytological evaluation using pap smear was done. However, pap smear findings were suggestive of inflammatory/non-neoplastic lesions in $44(88 \%)$ cases. They were unsatisfactory in $5(10 \%)$. One case was diagnosed as CIN III. As such cytology (Pap smear) is a less reliable tool for diagnosis of postmenopausal bleeding. ${ }^{18,19}$ Pap smear is generally performed as a routine test and its findings need to be corroborated with advanced diagnostic tools.

For this purpose, hysteroscopy was done. On hysteroscopy, half the cases $(n=25 ; 50 \%)$ were diagnosed as polyps followed by atrophic endometrium $(n=8 ; 16 \%)$. There were $7(14 \%)$ cases in whom the cervix was classified as unhealthy without any particular diagnosis. A total of $5(10 \%)$ cases were diagnosed as fibroid, 1 (2\%) each as hyperplasia and degenerative changes and 3 (6\%) as endometrial carcinoma. Hysteroscopic findings in different case series have shown wide diversity. Table 6 shows the hysteroscopic findings in postmenopausal bleeding cases in some of the contemporary studies:

An overview of Table 6 above shows a dominance of normal, atrophic and polyps in almost all the series. The rate of detection of endometrial carcinoma in different series ranges from $0 \%$ (Gupta et al) to $11.7 \%$ (Tandulwadkar et al). ${ }^{7,20}$ In present series, it was $6 \%$. In present study, rate of fibroid/myoma detection was only $10 \%$, however, some other workers detected it to be much higher, viz. Sarvi et al, detected it in $18.2 \%$ cases while Gupta et al, detected in $27.14 \% .^{20,21}$ However, some other workers like Sharma and Tiwari and Junnare et al, did not report it in any of their cases. ${ }^{9,22}$ Similarly, hyperplasia was reported in only $2 \%$ of this study cases, whereas Junnare et al, found it in $30 \%$ of their cases. ${ }^{9}$ The wide diversity in different pathologies in different studies could be owing to diversity in samples as well as sample size. Given a number of endometrial pathologies involved in postmenopausal bleeding, series with smaller sample size could have incidental rather than actual proportional representation.

In present study, final diagnosis was done by clinichistopathological correlation. On final diagnosis, in 1 (2\%) case, no abnormality was seen. There were 13 (26\%) cases diagnosed as atrophy, 22 (44\%) as polyps, 5 $(10 \%)$ each fibroid and endometrial carcinoma and 4 $(8 \%)$ as hyperplasia. As such, except for atrophy which was diagnosed in $26 \%$ cases hysteroscopically, no other major change in diagnosis was observed. However, Junnare et al, in their study found a major change in proportion of hyperplasia cases which were diagnosed in $30 \%$ cases hysteroscopically but were finally confirmed in only $11 \%$ cases. ${ }^{9}$ However, Tandulwadkar et al, showed excellent correlation between hysteroscopy and histopathology. ${ }^{7}$ Pop-Trajkoviü-Diniü on the other hand, found underdiagnosis of normal endometrium and endometrial polyp by hysteroscopy but an overdiagnosis for hyperplasia and atrophy as compared to histopathology. ${ }^{23}$ Sarvi et al, on the other hand found overdiagnosis of carcinoma in 2 out of 3 cases which were proven to be complex or atypical hyperplasia on histopathology. ${ }^{21}$ Although hysteroscopy is generally comparable to the final diagnosis in most of the cases, however, the advantage of the hysteroscopy lies in the fact that it allows endometrial biopsy through which the diagnosis could be confirmed histopathologically.

As compared to final diagnosis, hysteroscopy had a sensitivity and specificity of $100 \%$ and $89.3 \%$ respectively for polyps, $61.5 \%$ and $100 \%$ for atrophy, $100 \%$ and $100 \%$ for fibroids, $60 \%$ and $100 \%$ for endometrial cancer and $25 \%$ and $100 \%$ for hyperplasia. In their study, Rebeiro et al, reported the sensitivity and specificity of hysteroscopy to be $92.6 \%$ and $65.8 \%$ for polyps, $52.6 \%$ and $95.9 \%$ for fibroids, $94.4 \%$ and $97 \%$ for cancer or hyperplasia and $35.3 \%$ and $99.6 \%$ for normal endometrium. ${ }^{3}$ However, Tandulwadkar et al, in their study similar to present study, found $100 \%$ sensitivity and specificity for fibroids and $87.5 \%$ and $98.1 \%$ for endometrial carcinoma. ${ }^{7}$ In present study, the sensitivity for hyperplasia was quite low (25\%) however, Tandulwadkar et al, reported it to be $100 \% .^{7}$ PopTrajkoviü-Diniü reported the sensitivity and specificity of hysteroscopy for different pathologies in the range 91.4$100 \%$ and $96 \%-100 \%{ }^{23}$ Although authors could not achieve sensitivity and specificity to that extent. In present study, sensitivity was relatively much lower for hyperplasia and endometrial cancer. One of the reasons for this could be small number of sample size and fewer number of cases with these pathologies. Nevertheless, hysteroscopy coupled with endometrial biopsy is a useful tool for the evaluation of postmenopausal bleeding. Further studies on larger sample size might help in overcoming the limitation of incidental fluctuations in sensitivity and specificity.

\section{CONCLUSION}

Post-menopausal bleeding is one of the most common reasons for visit to a gynaecologist by a woman who has attained menopause. The recommended guidelines suggest clinical, hormonal and transvaginal sonography as the primary diagnostic tools. Sonography is considered to be adequate for evaluation of postmenopausal bleeding in cases where endometrial thickness does not exceed 4 $\mathrm{mm}$. However, in cases where endometrial thickness is $>4 \mathrm{~mm}$, further evaluation through sonohysteroscopy, office hysteroscopy or endometrial sampling is recommended.

Hysteroscopy is an office procedure, that can be performed as a day care procedure, provides a better view of various structural pathologies and in case of a doubtful pathology helps in obtaining endometrial sample to confirm the diagnosis. Hysteroscopy helps to identify the women who with postmenopausal bleeding having an abnormal pathology from those who do not have any such pathology. Along with endometrial biopsy it is considered to be highly accurate in identification of 
endometrial neoplasia and its precursors. It has been considered to be the method of choice for evaluation of women with postmenopausal bleeding especially those aged 45 years or above.

The present study was carried out to evaluate hysteroscopic findings in women with post-menopausal bleeding in order to ascertain various causes of PMB and to determine their prevalence in our population. For this purpose, a total of 50 women with complaints of postmenopausal bleeding were enrolled and were subjected to thorough history taking, clinical and biochemical evaluation followed by hysteroscopic evaluation, and wherever necessary endometrial biopsy was taken. Final diagnosis was established with the help of clinichistopathological work-up. The findings of present study suggested that hysteroscopy has a useful role in evaluation of postmenopausal bleeding especially in the diagnosis of polyps and fibroids. Given fewer number of cases, the usefulness of hysteroscopy in evaluation of endometrial cancer and hyperplasia could not be established adequately. Further studies on larger number of sample size will help in providing more useful and confirmatory information.

Funding: No funding sources Conflict of interest: None declared

Ethical approval: The study was approved by the Institutional Ethics Committee

\section{REFERENCES}

1. Research on the menopause in the 1990s: report of a WHO scientific group. WHO Tech Report Series. 1996;866:1-107.

2. Astrup K, Olivarius NDF. Frequency of spontaneously occurring postmenopausal bleeding in the general population. Acta Obstet Gynaecol Scand. 2004;83:203-7.

3. Ribeiro CT, Rosa-E-Silva JC, Silva-de-Sá MF, RosaE-Silva AC, Poli Neto OB, Candido Dos Reis FJ, et al. Hysteroscopy as a standard procedure for assessing endometrial lesions among postmenopausal women. Sao Paulo Med J. 2007;125:338-42.

4. Metello J, Relva A, Milheras E, Colaço J, Retto H. Hysteroscopic diagnostic accuracy in postmenopausal bleeding. Acta Med Port. 2008;21:4838.

5. Cordeiro A, Condeco R, Leitao C, Sousa F, Coutinho $\mathrm{S}$, Silva MC, et al. Office hysteroscopy after ultrasonographic diagnosis of thickened endometrium in postmenopausal patients. Gynecol Surg. 2009;6:317.

6. Tinelli R, Tinelli FG, Cicinelli E, Malvasi A, Tineli A. The role of hysteroscopy with eye-directed biopsy in postmenopausal women with uterine bleeding and endometrial atrophy. Menopause. 2008;15(4 Pt 1):737-42.
7. Tandulwadkar S, Deshmukh P, Lodha P, Agarwal B. Hysteroscopy in postmenopausal bleeding. J Gynecol Endosc Surg. 2009;1(2):89-93.

8. Nagalakshmi M, Malathi P, Sowjanya A. Evaluation of postmenopausal bleeding by using Pipelle curette and hysteroscopic-guided biopsy: a comparative study. J. Evid. Based Med. Healthc. 2016;3(74):4028-33.

9. Junnare KK, Desai GJ, Shekhawat GS. Hysteroscopy: an effective tool in post-menopausal bleeding. Int J Reprod Contracept Obstet Gynecol. 2019;8(1):159-64.

10. Viswanathan M, Daniel S, Shailaja M, Nazeema A. Socio-demographic profile of patients with postmenopausal bleeding attending out-patient unit of a tertiary care centre. Sch J App Med Sci. 2014;2(2C):681-4.

11. Sindhuri R, Dongre AR. Postmenopausal bleeding among rural women in Tamil Nadu, India: Mixed methods study. Indian $\mathrm{J}$ Community Med. 2018;43:288-93.

12. Cappelletti M, Wallen K. Increasing women's sexual desire: The comparative effectiveness of estrogens and androgens. Horm Behav. 2016;78:178-93.

13. Roeca C, Al-Safi Z, Santoro N. The Postmenopausal Women. InEndotext. MDText. com, Inc.; 2018.

14. Izetbegovic S, Stojkanovic G, Ribic N, Mehmedbasic E. Features of postmenopausal uterine haemorrhage. Med Arch. 2013;67(6):431-4.

15. Breijer MC, Timmermans A, van Doorn HC, Mol BWJ, Opmeer BC. Diagnostic strategies for postmenopausal bleeding. Obstet Gynecol Inter. 2010; Article ID 850812:1-5.

16. Jimenez AR, Rolon M del MR, Eyzaguirre E, Clement C. Vaginal bleeding as initial presentation of an aggressive renal cell carcinoma: a case report and review of the literature. Case Reports Pathol. 2018; Article ID 2109279:1-4.

17. Oriel KA, Schrager S. Abnormal uterine bleeding. Am Fam Physician. 1999;60(5):1371-80.

18. Bronz L, Dreher E, Almendral A, Studer A, Haller U. Guideline for the diagnosis of postmenopausal bleeding. PMPB Working Group of the SGGG. Gynakol Geburtshilfliche Rundsch. 2000;40(2):71-9.

19. Dutta A, Farrakh S, Rajasekar S. Postmenopausal bleeding: a blessing in disguise. J Clin Gynecol Obstet. 2014;3(4):141-2.

20. Gupta S, Sanyal P, Dasgupta S, Sarkar D, Das T, Mandal DD, et al. The ideal investigative method for evaluation of abnormal uterine bleeding in peri and post-menopausal women. J Evolut Med Dent Sci. 2015;4(17):2878-84.

21. Sarvi F, Alleyassin A, Aghahosseini M, Ghasemi M, Gity S. Hysteroscopy: a necessary method for detecting uterine pathologies in post-menopausal women with abnormal uterine bleeding or increased endometrial thickness. Turk J Obstet Gynecol. 2016;13(4):183-8.

22. Sharma J, Tiwari S. Hysteroscopy in abnormal uterine bleeding vs ultrasonography and 
histopathology report in perimenopausal and postmenopausal women. J Nepal Med Assoc. 2016;55(203):26-8.

23. Pop-Trajkoviü-Dinic S, Ljubic A, Kopitovic V, Antic V, Stamenovic S, Pjevic AT. The role of hysteroscopy in diagnosis and treatment of postmenopausal bleeding. Vojnosanit Pregl. 2013;70(8):747-50.
Cite this article as: Mansingh $\mathrm{S}$, Dhillon AS, Sood S, Anne S, Godi P. Hysteroscopic evaluation of postmenopausal bleeding patients and its correlation with histopathological examination. Int J Reprod Contracept Obstet Gynecol 2020;9:3215-22. 